\title{
Some Factors Influencing the Rumen Microbial Population
}

\author{
By A. C. I. WARNER \\ Division of Animal Physiology, C.S.I.R.O., Ian Clunies Ross Animal Research \\ Laboratory, Prospect, N.S.W., Australia
}

(Received 24. July 1961)

\section{SUMMARY}

In sheep fed once daily, the concentrations of micro-organisms in the rumen changed with the time after feeding, some organisms fluctuating in numbers more than others; peak concentrations were reached at different times for different organisms. These changes in concentration were reflected in changes in the proportion of dividing cells, for example, in Dasytricha ruminantium this proportion varied from less than $\mathbf{0 \cdot 2} \%$ throughout most of the day to a maximum of $23 \%$ a few hours before feeding; for Entodinium spp. the variation was less: it was possible to calculate the minimum doubling time for these latter organisms as about $5 \mathrm{hr}$.

One animal at different times, or different animals, on the same ration and dietary regime had very different rumen microbial populations, these differences being particularly marked in the case of some organisms. Reasons why these marked differences in microbial population are not reflected in similarly marked differences in over-all rumen metabolism are discussed.

Feeding different quantities of the same ration had little effect on the concentration of rumen microbes, provided the ration was above a minimal level; it is, however, suggested that output of microbial cells from the rumen may have varied with the amount of feed given. Starvation for a few days or prolonged under-nutrition had a marked effect, some organisms being drastically reduced in numbers or dying out completely. When the qualitative nature of the diet was changed, about 10 days were needed to complete the major adjustments in the rumen microbial population.

\section{INTRODUCTION}

Two factors influencing the numbers and kinds of micro-organisms within the rumen have been widely recognized as of importance: the nature of the ration and the time interval since feeding. Mowry \& Becker (1930) noted a considerable increase in the numbers of protozoa on adding starch and protein to a hay diet, while the effects of different kinds and amounts of protein, with or without starch, on the total bacterial count have been investigated by Moir and co-workers (Moir \& Williams, 1950; Williams \& Moir, 1951 ; Williams, Nottle, Moir \& Underwood, 1953). Qualitative differences in the rumen bacterial population with different rations have been noted by Quin (1943), Elsden (1945) and Pounden \& Hibbs (1948 a, b), while quantitative differences in a number of groups of bacteria have been found by Gall, Burroughs, Gerlaugh \& Edgington (1949), Burroughs, Gall, Gerlaugh \& Bethke (1950), Spisni (1955) and Maki \& Foster (1957). However, no clear principles have emerged except that alterations to the ration are accompanied by alterations to 
the microbial population, with rations richer in readily attacked nutrients supporting greater numbers. Eadie, Mann \& Oxford (1956) have shown that certain terpenes and other substances that could be present in plant material have marked toxic properties towards the rumen protozoa. Diurnal fluctuation of microbial numbers, related to the time after feeding, is also commonly recognized though detailed figures are rare in the literature. Both the magnitude and the pattern of the fluctuations vary with the nature of the ration (Johnson, Hamilton, Robinson \& Garey, 1944; Nottle, 1956; El-'Tabey Shehata, 1958). Purser \& Moir (1959) found diurnal rhythms in the concentration ol entodinia and of dividing entodinia, and claimed that the $\mathrm{pH}$ of the rumen was the main controlling factor; however, Purser (1961) found a quite different rhythm lor the concentration of dasytrichs.

In addition to these factors influencing the population Moir \& Somers (1957) have shown that the feeding regime influences bacterial and protozoal numbers, and the diurnal fluctuations of bacterial numbers. Nottle (1956) has claimed to have found seasonal fluctuations in bacterial numbers, though the number of observations was not very large and other causes of the fluctuations cannot be excluded.

Finally, a number of authors have noted differences in microbial numbers from day to day, and individual differences between animals on the same ration. Enormous differences in protozoal concentrations were described by Williams \& Moir (1951), though Oxford (1955b) claimed that these must be due to technical errors, and indeed later protozoal counts from the same laboratory, using a different technique (Moir \& Somers, 1957) show no evidence of similar variability. Mowry \& Becker (1930) and Purser \& Moir (1959) had also noted differences in protozoal counts between days and between animals, and Boyne, Eadie \& Raitt (1957) found differences in protozoal concentration from day to day. Differences in bacterial concentration between days or between animals have been less marked, usually 1.5- to 3-fold (Williams \& Moir, 1951; Nottle, 1956). While it has been customary to pay only statistical attention to these variations, the possibility that the day-today differences in microbial numbers are among the causes of fluctuations in digestibility coefficients of the kind found by Lloyd, Peckham \& Crampton (1956), and that the differences between animals are among the causes of individual differences in digestive efficiency, cannot be excluded.

In this paper a number of factors that might influence the rumen microbial population are examined, paying particular attention to the protozoa and the morphologically distinctive large bacteria and other protists.

\section{METHODS}

Sampling. The methods used were those of Warner (1962) except that samples from some sheep $(41,47,49)$ were collected through a stomach tube and that, in the experiment investigating diurnal changes, it was felt desirable to get a better approximation to the true count than was obtainable by the standard technique, but without subjecting the animal and its rumen micro-organisms to the trauma of total emptying of the rumen several times in one day. A compromise sample was obtained by removing about $800 \mathrm{~g}$. rumen contents through a fistula of $5 \mathrm{~cm}$. diam.; care was taken, by mixture of the solid and fluid portions, to have the consistency 
of this sample as close as possible to that of the rumen contents. About $50 \mathrm{~g}$. of this sample were added to $200 \mathrm{ml}$. of formol saline, the remainder being returned to the animal. The formol saline was then strained through nylon bolting cloth. The solids were re-suspended in formol saline, mixed well and strained again. The washings were centrifuged, first at $50 \mathrm{~g}$ for $5 \mathrm{~min}$., then at $4500 \mathrm{~g}$ for $45 \mathrm{~min}$., both deposits being mixed with the original strained sample and the final supernatant discarded. The solids were then blended for $4 \mathrm{~min}$. with four successive batches of $50 \mathrm{ml}$. formol saline, straining each mixture; finally the remaining solids were blended for $4 \mathrm{~min}$. with $100 \mathrm{ml}$. formol saline, the mixture centrifuged at $50 \mathrm{~g}$ for $5 \mathrm{~min}$. and both the supernatant and the bulky deposit were strained. All these blended extracts were then pooled and centrifuged at $4500 \mathrm{~g}$ for $45 \mathrm{~min}$. and the deposits were mixed with the original strained sample. Counts on this final preparation were called 'bulk' counts. The ratio of the bulk count to the standard count was not quite the same as the ratio of the true count to the standard count found in similarly fed animals by Warner (1962); however, it is not known to what extent this was due to the differences in technique.

Microbial counts were made as described by Warner (1962).

Note on some of the organisms counted. The oligotrich ciliate protozoa have been named following Lubinsky (1957).

The organisms described as polymastigates in this paper are protozoa probably of the genus Callimastix Weissenberg.

The organisms described as flagellates are oval cells, $8 \cdot 8 \pm 0 \cdot 4 \times 7 \cdot 4 \pm 0 \cdot 3 \mu$ in formolized samples, dividing by transverse fission, motile though with no flagella visible in unstained preparations, and with no internal structures when viewed in unstained preparations under direct or phase contrast illumination. They are possibly flagellate protozoa. They are not to be confused with the organisms that Moir and co-workers call 'flagellates'-in their terminology, this refers (Moir \& Somers, 1957) to the organisms described in this paper as selenomads (organism no. 3-5 of Moir \& Masson, 1952). This organism is of uncertain status, indeed, several morphologically similar organisms may be involved (Oxford, $1955 \mathrm{a}$ ).

The organisms described here as streptococci are large cocci in chains, organism no. 27 of Moir \& Masson (1952), possibly identical with the organism LC of Elsden, Volcani, Gilchrist \& Lewis (1956) and named Peptostreptococcus elsdenii by Gutierrez, Davis, Lindahl \& Warwick (1958). These were counted as chains, not as individual cells: the chains were of fairly uniform length, mostly about 6-10 cells.

Animals. Except where otherwise noted, the animals were Merino or MerinoEnglish Leicester cross-bred ewes or wethers fed on various amounts of the ration R. 9. This consists of equal parts of lucerne chaff and wheaten chaff. It is satisfactorily stable, and by the usual tests of gross composition and metabolism by the animal, it is satisfactorily constant in composition from batch to batch or from time to time.

\section{RESULTS}

Differences in rumen microbial population in animals on a constant ration

Seasonal and daily changes. Standard counts done on rumen contents collected from one animal under standard conditions over a period of 21 months are shown in Table 1. Counts of all organisms showed changes from time to time, much more 


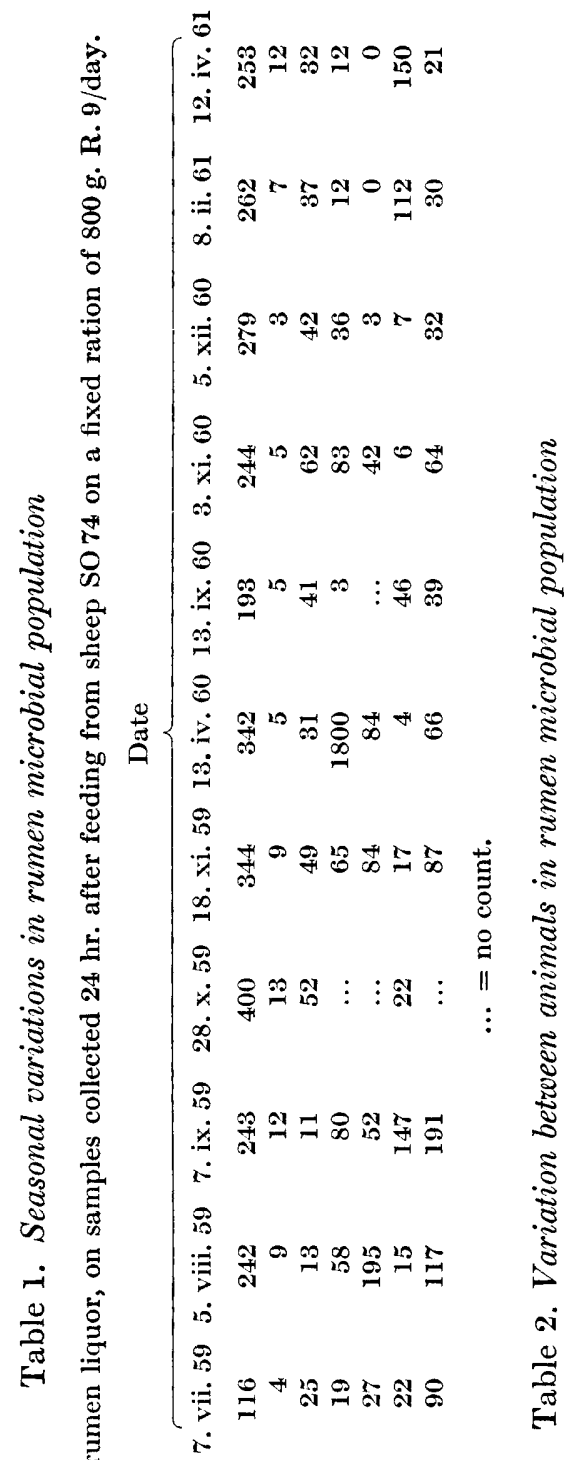

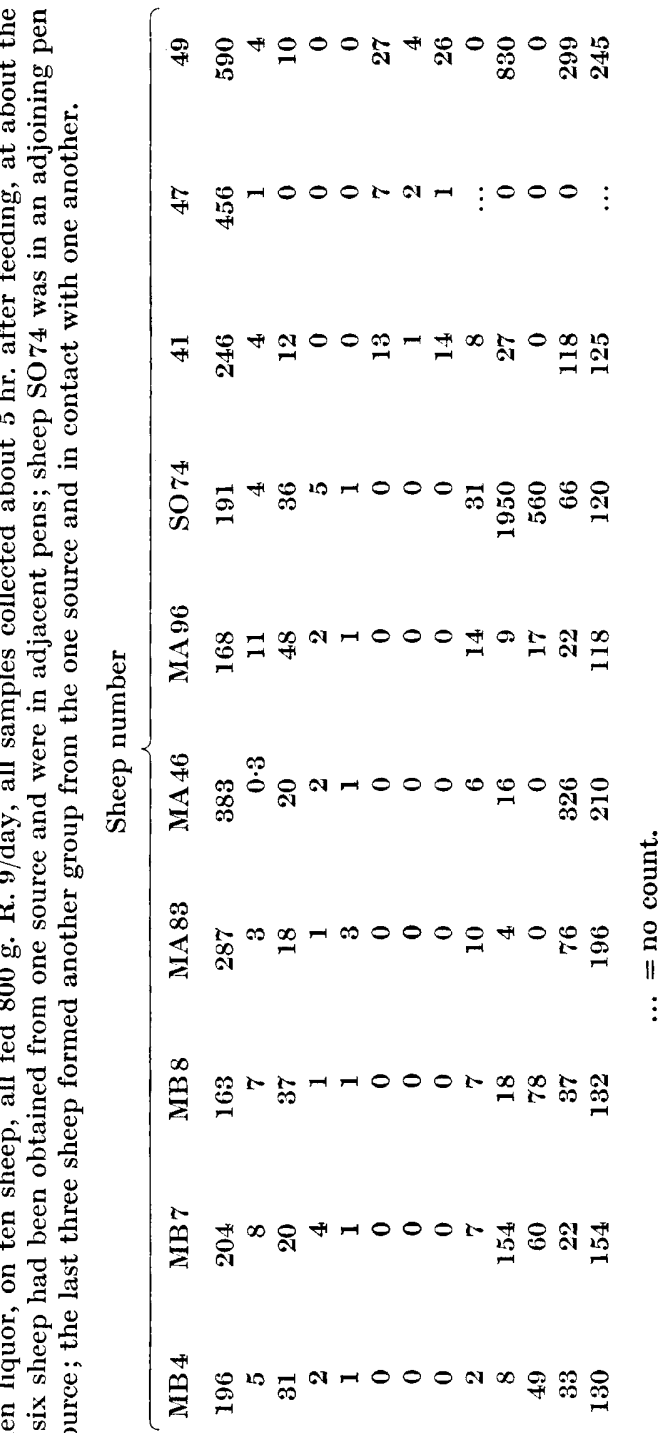

$\dot{\Xi}$

हं

过

㱐

寻

응

焉范

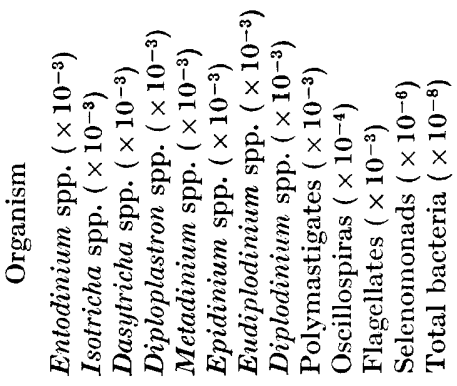


marked in, e.g. oscillospiras than in, e.g. entodinia, but there is no evidence of any rhythm. Counts made on consecutive days showed smaller, though still on occasion statistically significant, changes. It is, of course, possible that some of these changes were due to differences in composition of the ration as fed since several different batches were used. However, changes in batches of materials for the ration were not associated with any major change in microbial population; and major changes in population were not associated with any recognizable change in the ration.

Differences between animals. Standard counts done on rumen contents collected under standard conditions from different animals on identical rations are shown in Table 2.

Quantitative differences are noticeable, the more marked differences occurring in those organisms found previously to show most day-to-day variation. These differences were not merely artefacts due to the use of the relatively inaccurate standard technique, since they were confirmed, in six out of the ten cases, by true total counts using the method of Warner (1962). Qualitative differences also were found, some organisms being present in the rumens of some animals and absent in others, the absence being confirmed by prolonged search. The association of Metadinium spp. with Diploplastron spp., or the alternative association of Epidinium spp.Diplodinium spp. and Eudiplodinium spp. has been found in about thirty animals, suggesting at least some measure of mutual exclusiveness.

To examine some possible causes of these quantitative differences between animals, the entire rumen contents were removed from six animals fitted with $5 \mathrm{~cm}$. diameter fistulas, and interchanged in pairs. The results of a typical pair are shown in Table 3. These and the other data show that the microbial populations were considerably disturbed by the operation; the concentrations fluctuated widely in a very short time. Nevertheless, some organisms, e.g. selenomonads, tended to re-establish themselves in the concentrations characteristic of the host animal, being, for example, much more numerous in sheep MA86 than in sheep MB 8 at the beginning and at the end of the experiment; similar results were obtained with the other animals. On the other hand other organisms, e.g. entodinia, tended to re-establish themselves in concentrations more like those of the donor animal.

Rumen liquor from one animal was incubated in vitro for up to $12 \mathrm{hr}$. with an equal volume of saliva or of rumen liquor clarified by high-speed centrifugation from the same or another animal; in several such experiments no specific inhibitory or stimulatory effects on any of the micro-organisms could be detected.

Diurnal changes related to feeding. Standard and bulk counts were made on sheep MA94, at various times after feeding. The animal had for some time been on a ration of $800 \mathrm{~g}$. R. $9 /$ day; on the 2 days of the experiment this was increased to $1000 \mathrm{~g}$. R. 9/day to compensate for the material removed by sampling; water consumption was unrestricted. The results are shown in Fig. 1. Four points should be noted:

(i) The counts on the second day were fairly similar to those on the first, suggesting no great damage to the micro-oganisms due to the sampling procedure.

(ii) Some organisms, e.g. streptococci, varied in concentration much more than others, e.g. oscillospiras.

(iii) The peak concentrations were reached at rather different times for different organisms and the patterns of rise and fall were different. 


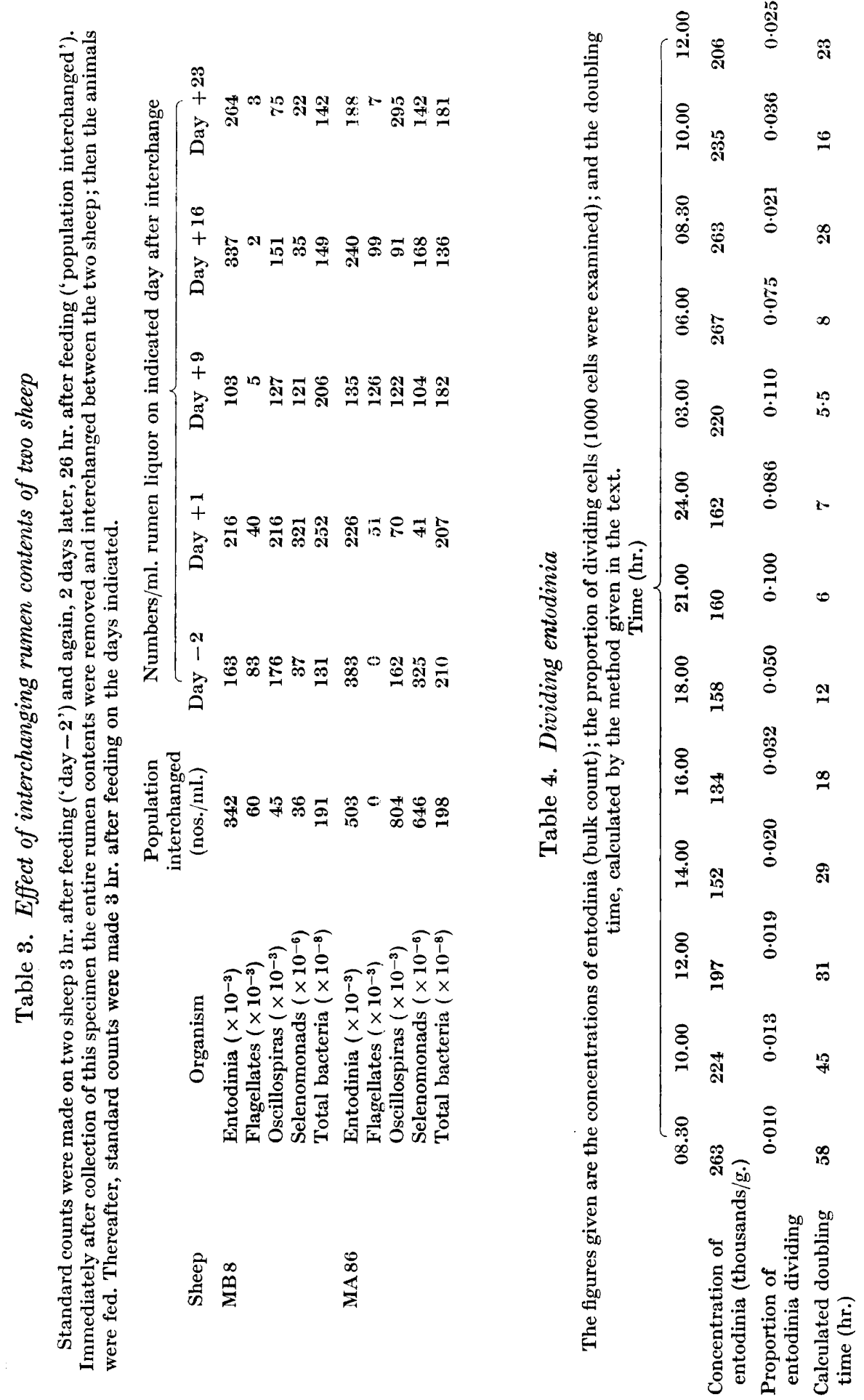




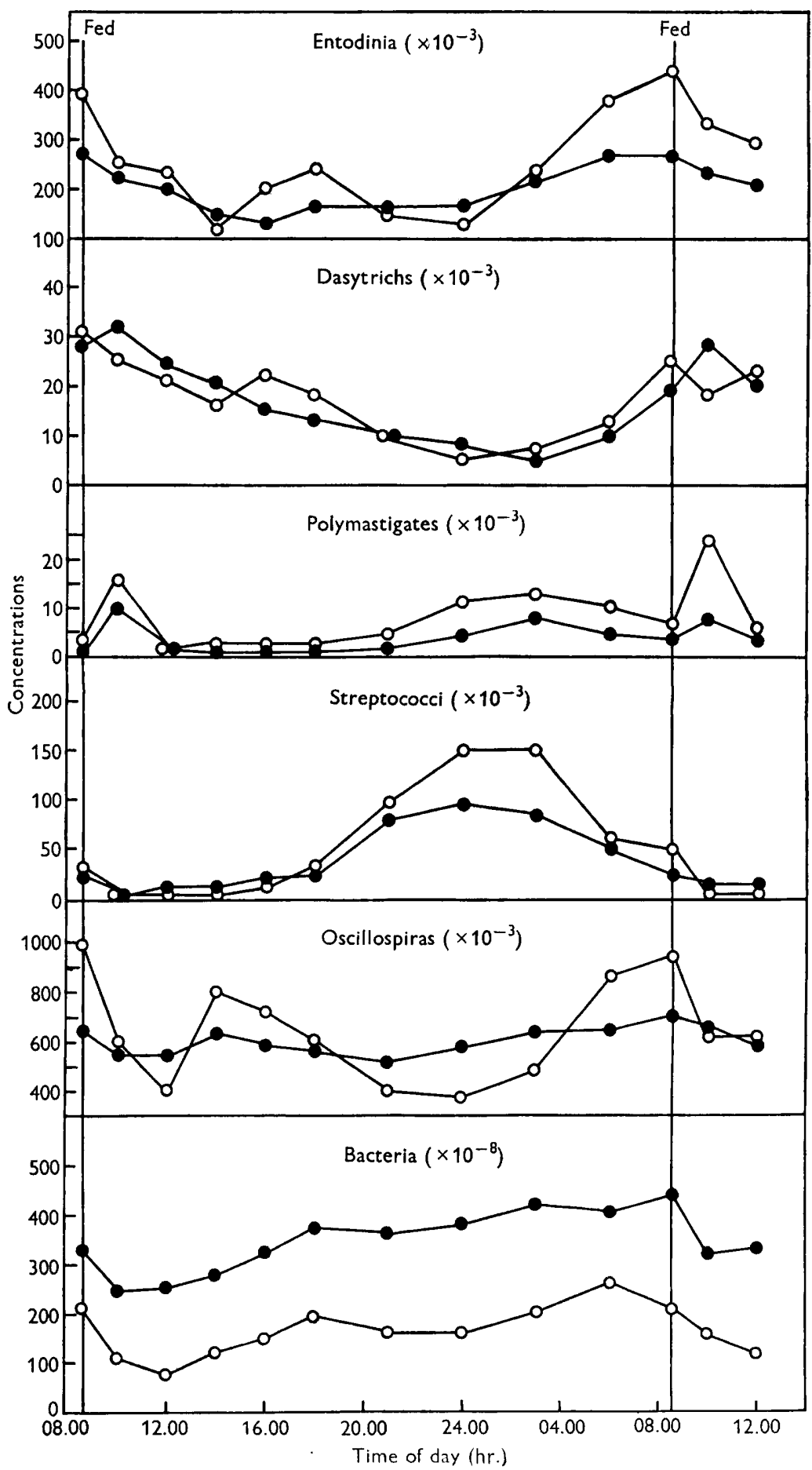

Fig. 1. Diurnal changes related to feeding in concentrations of rumen micro-organisms. - = bulk count (no./g.); $\bigcirc-\mathrm{O}=$ standard count (no. $/ \mathrm{ml}$.). 
(iv) The bulk counts showed less variation than the standard counts; the ratios of bulk to standard counts for three groups of organisms are shown in Fig. 2; similar trends can be noted for the different groups of organisms. These ratios are not given for the remaining three groups of organisms because their low numbers at times made the counts too inaccurate for reliable calculation of the ratio.

An incidental finding of some interest concerns the rate of division of the protozoa. It was first noted that there was a very high proportion of dividing dasytrichs in the $06.00 \mathrm{hr}$. sample, 0.23 of the population, and to a less extent in the $03.00 \mathrm{hr}$. sample, $0 \cdot 09$, when numbers were increasing most rapidly, contrasting with the negligible proportion found at all other times, only the second $08.30 \mathrm{hr}$. sample having more than 0.003 of the population dividing. Owing to the low concentration of these organisms making accurate counts difficult, and the early stages of division being hard to recognize, attention was concentrated on the entodinia.

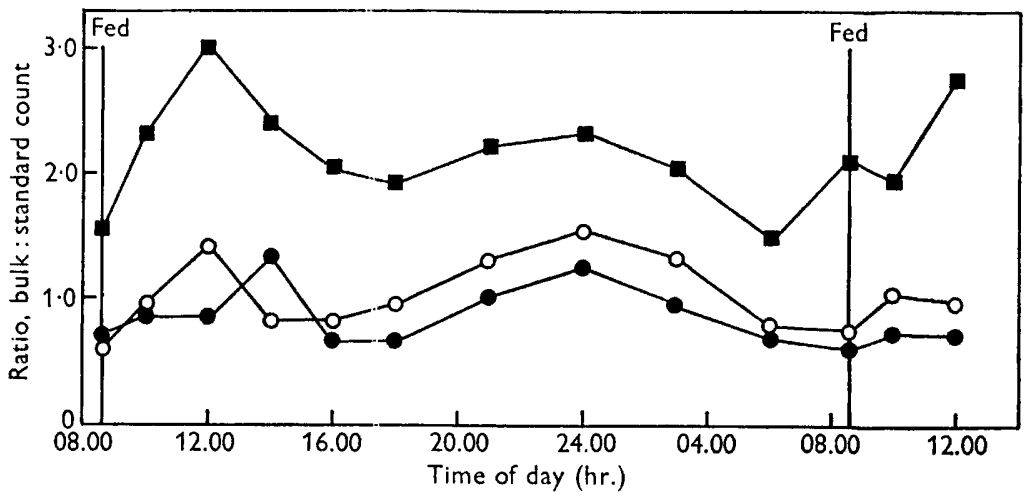

Fig. 2. Durnal changes related to feeding in the ratio of bulk to standard counts. $\longrightarrow-0=$ entodinia $; 0-0=$ oscillospiras; $\mathbf{\square}-\mathbf{\square}=$ bacteria.

The proportion of dividing entodinia also varied considerably from time to time, as shown in Table 4. These figures can be used to calculate the mean generation or doubling time. If use is made of a warm stage on the microscope, a dividing protozoon can be followed from the first apparent signs of cytoplasmic division to its completion; in a number of experiments done at different times of the day the time for this process in several species of entodinia appeared to be about $15 \mathrm{~min}$., with no marked change at different times; this figure is slightly lower than the figure of 15-25 min. obtained previously by Warner (1956); it is thought that better temperature control on the warm stage may be the explanation. Owing to the rapid motion of the protozoa, the early stages of division, easily detectable in formolized specimens, cannot be recognized in the living cells; but examination of formolized samples showed that about $30 \%$ of the dividing cells were at a stage that would be recognizable in a living preparation, and that this proportion did not alter markedly from time to time. Use can be made of a formula which was derived by Crick (1948) for mitoses in tissue cells and used by Scherbaum (1957) for dividing protozoa; this can be re-written as

$$
t_{d}=: \frac{\log _{e} 2 \cdot T}{\log _{e}(1+2 I) /(1+I)},
$$


where $t_{d}$ is the doubling time, $T$ is the time needed to complete division, and $I$ is the division index, i.e. the proportion of dividing cells. With this formula and the figures for $T$ and $I$, it is possible to calculate the doubling time of entodinia in the rumen. The results are given in Table 4.

Differences in rumen microbial population in animals receiving different rations

Changes in quantity of a single feed. For the purposes of another experiment, two sheep were fed varying quantities of the feed R. 9, receiving each ration for at least 3 weeks. During the last week of each period, two or three standard counts were

\section{Table 5. Effect of quantitative changes of ration}

Standard counts, per ml. rumen liquor, on two sheep fed indicated amounts of R. 9/day in two equal portions at 12-hourly intervals. Each period lasted at least 3 weeks; figures given are means of two or three counts during the last week, except for the estimation of the proportion of dividing entodinia, where only one count was made. All counts were made under standard conditions, $5 \mathrm{hr}$. after feeding.

Sheep 41

Organism

$\begin{array}{cccccccc}\text { Period } & \text { Period* } & \text { Period } & \text { Period } & \text { Period } & \text { Period } & \text { Period } & \text { Period } \dagger \\ 1, & 2, & 3, & 4, & 5, & 6, & 7, & 8, \\ 800 \mathrm{~g} . & 300 \mathrm{~g} . & 1200 \mathrm{~g} . & 900 \mathrm{~g} . & 600 \mathrm{~g} . & 300 \mathrm{~g} . & 800 \mathrm{~g} . & 1800 \mathrm{~g} . \\ 321 & 131 & 293 & 217 & 425 & 290 & 242 & 1664 \\ 0 \cdot 05 & 0 \cdot 05 & 0 \cdot 10 & 0 \cdot 07 & 0 \cdot 07 & 0 \cdot 03 & 0 \cdot 05 & \ldots \\ 8 & 7 & 12 & 7 & 8 & 2 & 10 & 0 \\ 7 & 2 & 9 & 9 & 15 & 11 & 13 & 0 \\ 1 & 1 & 3 & 1 & 2 & 1 & 1 & 0 \\ 4 & 0 \cdot 5 & 1 & 0 \cdot 5 & 1 & 1 & 3 & 0 \\ 23 & 8 & 26 & 27 & 34 & 12 & 14 & 0 \\ 14 & 6 & 9 & 7 & 15 & 6 & 9 & 0 \\ 871 & 223 & 433 & 59 & 106 & 71 & 17 & 6610 \\ 60 & 0 & 12 * & 136 & 367 & 87 & 118 & 0 \\ 97 & 181 & 200 & 195 & 147 & 132 & 152 & 361\end{array}$

Entodinium spp. $\left(\times 10^{-3}\right)$

Proportion of entodinia dividing

Epidinium spp. $\left(\times 10^{-3}\right)$

Diplodinium spp. $\left(\times 10^{-3}\right)$

Eudiplodinium spp. $\left(\times 10^{-3}\right)$

Isotricha spp. $\left(\times 10^{-3}\right)$

Dasytricha spp. $\left(\times 10^{-3}\right)$

Polymastigates $\left(\times 10^{-3}\right)$

Oscillospiras $\left(\times 10^{-4}\right)$

Selenomonads $\left(\times 10^{-6}\right)$

Total bacteria $\left(\times 10^{-8}\right)$

Sheep 49

\section{Organism}

Entodinium spp. $\left(\times 10^{-3}\right)$

Proportion of entodinia dividing

Epidinium spp. $\left(\times 10^{-3}\right)$

Diplodinium spp. $\left(\times 10^{-3}\right)$

Eudiplodinium spp. $\left(\times 10^{-3}\right)$

Isotricha spp. $\left(\times 10^{-3}\right)$

Dasytricha spp. $\left(\times 10^{-3}\right)$

Polymastigates $\left(\times 10^{-3}\right)$

Oscillospiras $\left(\times 10^{-4}\right)$

Selenomonads $\left(\times 10^{-6}\right)$

Total bacteria $\left(\times 10^{-8}\right)$

$\begin{array}{ccr}\text { Period } & \text { Period* } & \text { Perio } \\ 1, & 2, & 3, \\ 800 \text { g. } & 900 \text { g. } & 600 \text { g } \\ 480 & 426 & 368 \\ 0 \cdot 04 & 0 \cdot 05 & 0 \cdot 04 \\ & & \\ 17 & 20 & 6 \\ 13 & 12 & 10 \\ 4 & 3 & 1 \\ 2 & 2 & 1 \\ 0 & 0 & 0 \\ 4 & 6 & 1 \\ 4 & 22 & 527 \\ 428 & 135 & 98 \\ 216 & 220 & 200\end{array}$

Period

4,
$300 \mathrm{~g}$.

Period

Period

Period

$5, \quad 6, \quad 7$,

900 g. $1200 \mathrm{~g} . \quad 800 \mathrm{~g}$.

$\begin{array}{lllll}220 & 361 & 629 & 546\end{array}$

$\begin{array}{llll}0.03 & 0.06 & 0.04 & 0.07\end{array}$

$\begin{array}{rrrr}6 & 5 & 24 & 28 \\ 5 & 15 & 27 & 25 \\ 1 & 2 & 3 & 3 \\ 0 \cdot 5 & 0 \cdot 5 & 3 & 2 \\ 4 \$ & 18 & 52 & 12 \\ 1 & 6 & 5 & 1 \\ 144 & 104 & 423 & 533 \\ 95 & 120 & 225 & 283 \\ 207 & 173 & 180 & 223\end{array}$

* Between the first and second period 4 days' starvation followed by a recovery period of 14 days on 800 g. R. 9/day intervened.

$\dagger$ Between the 7 th and 8 th period, this animal had been starved for 4 days, then on 300 g. R. 9/day for 3 months, starved a further 4 days and then, with some difficulty, brought back to $1800 \mathrm{~g}$. R. 9/day; the animal had been eating normally for at least 5 weeks when the sample was taken.

$\ddagger$ Subsequent to the starvation period, selenomonads were not found in this animal for 53 days; the figure given is the mean of the first two samples to contain the organism.

$\S$ Throughout the first 3 months of this experiment, no dasytrichs were found in this animal. 
made under standard conditions; the means of these counts are given in Table 5 . They show some individual differences, sheep 41 having consistently fewer entodinia and bacteria than sheep 49. There is a suggestion that $300 \mathrm{~g}$. R. $9 /$ day produces a lowered concentration of micro-organisms, otherwise there does not appear to be any consistent effect on the concentrations of varying the ration between 300 and 1200 g. R. 9/day; there were, however, considerable fluctuations in concentrations, thought to be of the same kind as those discussed in the first experiments above. There was a tendency for the proportion of dividing entodinia to increase on increasing the ration.

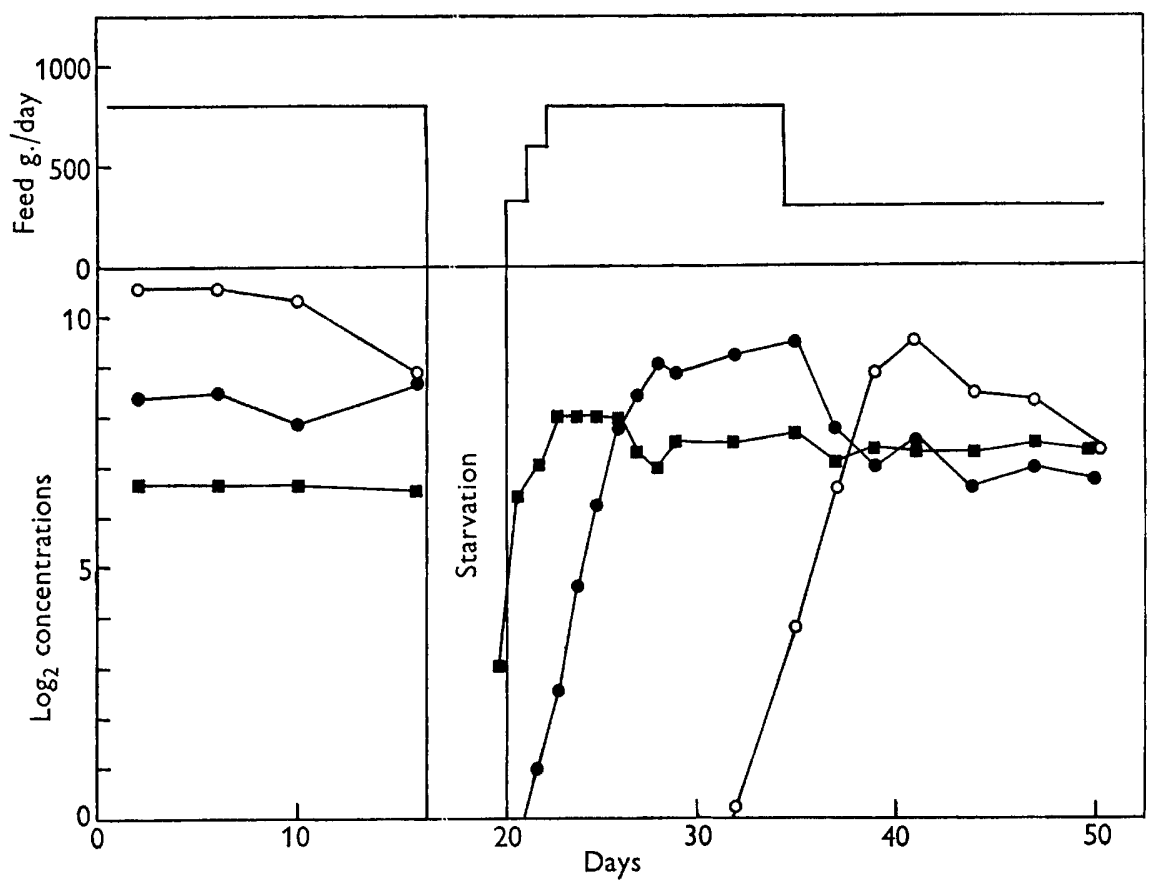

Fig. 3. Effect of starvation on rumen microbial concentrations. Standard counts were made $5 \mathrm{hr}$. after feeding. $-0=$ entodinia $\left(\times 10^{-3}\right) ; 0-\mathrm{O}=\operatorname{oscillospiras}\left(\times 10^{-3}\right)$; - $=$ bacteria $\left(\times 10^{-8}\right)$. The upper graph shows the amount of feed consumed/day.

In period 8 (sheep 41) an unusual microbial population developed following a prolonged period of undernutrition. Few species of organism were present, but those few were found in high concentrations.

Effect of starvation. During the course of the above-mentioned experiment, each animal was subjected to two periods of starvation of 4 days each. Typical results of counts made around such a period are shown in Fig. 3 and the times taken from the end of the starvation period to the reappearance of the organism (i.e. in numbers greater than about $200-500 / \mathrm{ml}$.) are shown in Table 6 .

Multiplication of the entodinia was such as to indicate upwards of four generations in a day even without making any allowance for the flow of rumen contents. Estimation of the division index for entodinia during this period of rapid multiplication gave figures up to $\mathbf{0} \cdot \mathbf{2 0}$; by calculations similar to those previously discussed, 
Table 6. Time needed for reappearance of micro-organisms following a period of starvation

Time in days from the end of the starvation period until the appearance of the organism in concentrations of at least $200 / \mathrm{ml}$. rumen liquor, for each of two animals and two starvation periods.

Organism

Entodinium spp.

Epidinium spp.

Diplodinium spp.

Eudiplodinium spp.

Isotricha spp.

Dasytricha spp.

Polymastigates

Oscillospiras

Selenomonads
Time of reappearance

$$
\text { (days) }
$$

$1,0, * 0,0$

$3,14,11,5$

$3,8,5,5$

$2,3,11,5$

$18,16,30,19$

$-, \dagger 18,18,19$

$7,7,30,7$

$11,7,11,19$

$22,53,0,19$

* The figure 0 means that the organisms did not at any time disappear from the rumen.

$\dagger$ No dasytrichs were found before or immediately after this starvation period.

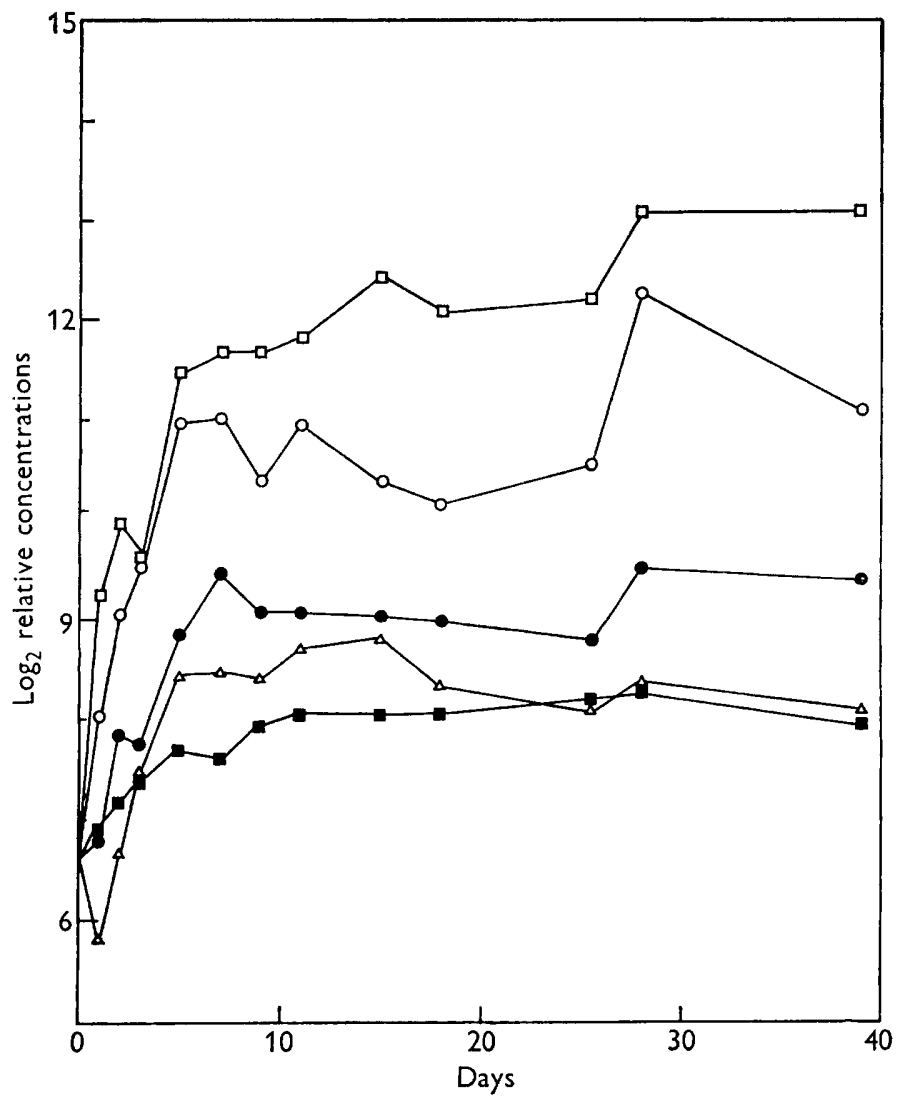

Fig. 4. Changes in the rumen microbial population in a Cheviot sheep on altering the ration from hay $(900 \mathrm{~g}$./day) to hay plus concentrates (hay: $300 \mathrm{~g}$., groundnut meal: $300 \mathrm{~g}$., flaked maize : $300 \mathrm{~g} . / \mathrm{day})$. Standard counts were made on samples taken $5 \mathrm{hr}$. after feeding. The figures were expressed as relative to a count of 100 on day 0 (the last day on the hay ration) and then converted to their logarithms to the base 2 . - entodinia $; \bigcirc-O=$ oscillospiras; $\square-\square=$ bacteria $\square-\square=$ total holotrich protozoa: $\triangle-\triangle=$ selenomonads. 
this corresponds to a doubling time of about $3 \frac{1}{2} \mathrm{hr}$., about seven generations/day if maintained.

Effect of a complete change of ration. In common with other workers, it has been found in the course of this work that different animals on different rations have different rumen microbial populations. However, in view of the considerable variations already found between animals on the one ration, it seems of little value to publish the results of a very small number of counts done on a very smail number of animals on any one ration. Hut in one case a series of counts was made on an animal whose ration was being changed from hay alone to hay plus concentrates, and the results are shown in Fig. 4. All groups of micro-organisms increased in numbers to between 3 - and 60 -fold their initial concentration, but the maximum net growth rate corresponded to a doubling time of only 1 day, to be compared with about $6 \mathrm{hr}$. in the starvation recovery experiments reported above. All major changes seemed to have ceased after about 10 days; this is consistent with common experience that about this period is usually needed for adaptation to a new diet in the ruminant.

\section{DISCUSSION}

Influence of the ration. While the influence of the ration on the concentrations of rumen micro-organisms is undeniable, it would appear from this work that this influence is due more to the qualitative nature of the ration than to purely quantitative factors, and secondly, that other factors, still largely undefined, can exert a profound influence on both the qualitative and the quantitative nature of the rumen microbial population.

It should be noted throughout this work that it is changes in microbial concentrations that have been measured. Changes in the volume of rumen contents are known to take place from time to time throughout the day, and to accompany some changes in ration (Emery, Smith \& Lewis, 1958). Similarly, it is possible that the different dietary regimes were accompanied by different flow rates through the rumen, which in any case is not constant through the day, due to different rates of consumption of water or of secretion of saliva.

Hence similar concentrations of micro-organisms could be associated with different outputs of microbial cells, though it is not to be expected that such differences would normally exceed a factor of perhaps four at the most. Therefore it is possible that, in the experiment described in Table 5, the microbial output may have been proportional to the amount of the ration, even though the concentration showed little or no such proportionality.

However, while the different microbial outputs may not have varied precisely as the concentrations in the experiments described by Tables 1 and 2 and Figs. 1 and 4 , the major changes in concentration must reflect considerable changes in output since they are much greater in magnitude than the changes in rumen volume or flow rate, and some at least of the minor changes in concentration must reflect changes in output since they occul: at different times or vary in opposite senses.

Origin of rumen micro-organisms. It is generally agreed that most of the protozoa and many of the bacteria of the rumen are found only in that habitat, and fairly direct contact between animals must take place for infection by any given species to occur. Hence if, as a result of starvation, etc., any species is lost from the 
rumen, contact with normal animals would be needed to reinfect the experimental animal.

In the experiment whose results are recorded in Tables 5 and 6 , sheep 49 had no dasytrichs when first examined nor for 3 months thereafter; they then appeared and increased to concentrations comparable with those in sheep 41 on a similar diet. This would appear to be a case of either a new infection or perhaps a re-infection following loss at some time prior to commencement of the experiment. The animals were normally kept in single pens or metabolism crates close to one another; no special care was taken to keep the animals isolated and some degree of contact was possible.

In this same experiment, the smallest concentration that could be detected was about $200 / \mathrm{ml}$, , corresponding to about $10^{6}$ or $2^{20}$ organisms in the whole rumen (assuming a rumen volume of $5000 \mathrm{ml}$.). At the time of re-appearance, net doubling time has been less than 1 day for all organisms, so that even starting from a single cell, only about 20 days would be needed for obvious reappearance. Some lag is perhaps to be expected, but the $\mathbf{5 3}$ days needed on one occasion for the reappearance of selenomonads would seem to be almost certainly a case of complete loss followed by accidental re-infection; some of the other longer periods might also be in this category.

The order of reappearance of the ciliate protozoa, entodinia before other oligotrichs before holotrichs, is similar to that found in cattle following 3 days' starvation, oligotrichs before holotrichs (Meiske, Salsbury, Hoefer \& Luecke, 1958) and is also similar to the order of first establishment in calves, entodinia before diplodinia before holotrichs (Bryant, Small, Bouma \& Robinson, 1958). The lengthy disappearance of polymastigates on one occasion is in contrast with the experience of Becker, Schulz \& Emmerson (1930) who found the flagellate protozoa very difficult to keep out of the rumen in their defaunation experiments. On the other hand, their treatment removed oscillospiras and re-inoculation was needed, whereas in the present experiments they recurred spontaneously after a moderate absence.

There is a tendency for the numbers of microbes, on refeeding after starvation, to rise to a peak and then decline a little (Fig. 3 is typical of four such experiments); there is some suggestion of a similar overshooting in metabolic activity in the experiments of Meiske et al. (1958).

Diurnal changes in the microbial population. Both the magnitude and the pattern of the diurnal changes in the concentrations of the rumen micro-organisms differ with the organism (Fig. 1). The pattern of changes in concentration of dasytrichs and entodinia was similar to that found by Purser (1961), and by Purser \& Moir (1959), respectively. The pattern of changes in the bacterial concentration was similar to the patterns found by Nottle (1956) and El-Tabey Shehata (1958) for sheep fed chaff and concentrates containing casein, though unlike the pattern with other concentrates.

Present data are inadequate to allow of any but the most speculative of explanations of these findings.

The ratio of the bulk count to the standard count also varied with time (Fig. 2). Warner (1962) found a similar increase in the ratio of the true total count to the standard count a few hours after feeding, as compared with a fasting specimen. In the case of bacteria these changes could be due to some extent to changes in the 
ratio of 'fixed' to 'free' organisms, freshly ingested feed being rapidly colonized. The ability of the feed residues to act as a filter during the preparation of the standard sample would also vary with time, and this could account for some others of these variations. If the bulk count can be taken as a reasonable approximation of the true count, then it would appear that the standard count can be particularly misleading as a guide to the true count in the case of the entodinia and the oscillospiras, over-emphasizing the fluctuations in concentration.

The spectacular increases in the proportion of dividing dasytrichs at $06.00 \mathrm{hr}$. and in the concentration of streptococci at $24.00 \mathrm{hr}$. $-03.00 \mathrm{hr}$. (Fig. 1) indicate marked periodicity in the growth cycle of these organisms. There was a less-wellmarked periodicity in the proportion of dividing entodinia, with a peak at 21.00$03.00 \mathrm{hr}$. (Table 4). Again, an explanation awaits further information. Purser \& Moir (1959) noted changes in the concentration (and, by my calculation, the proportion) of dividing entodinia less marked than found here. They believed that the $\mathrm{pH}$ of the rumen contents was the main controlling factor though this could not explain all their results. In any case, implication of the hydrogen ion rather than, e.g. the propionate ion (see Stross, 1960) or some other factor, as the cause of the initial decline in division rate after feeding seems unwarranted at this stage.

Just as the dividing forms of the rumen ciliate protozoa occur normally rarely but at times become very frequent, so do conjugating forms. Normally seen very rarely, on a few occasions in this work conjugation has become frequent, particularly with the dasytrichs; there appeared to be no obvious common factor between the occasions when this was observed.

The minimum mean doubling time for the entodinia (Table 4) was $5 \cdot 5 \mathrm{hr}$, i.e. maximum rate of division corresponded to about four generations per day, as compared with up to seven generations per day during recovery from starvation. These figures may be compared with the best division rates found in cultures of rumen ciliates, about two generations per day for Epidinium ecaudatum (Gutierrez, 1959), the most rapid growth so far recorded for any rumen ciliate in culture, or one generation in two to four days for mixed Entodinium spp. (Coleman, 1958); it would seem that conditions in these cultures were still far from optimal for the multiplication of these organisms.

Variability in numbers of some species. Inspection of Tables 1 and 2 shows that even with one animal on a constant ration there is no species of micro-organism that maintains constancy of concentration. Some species, such as the metadinia or the epidinia, may be present in moderate numbers or completely absent. Others, such as the oscillospiras or selenomonads, are usually present but in numbers varying very considerably. Yet others, such as the entodinia, are always present in fairly similar numbers.

There are some indications of a specific animal effect. When rumen contents were interchanged between two sheep, there appeared to be a tendency for some organisms to re-establish in concentrations characteristic of the host animal (Table 3). Again, in the experiment recorded in Table 5 , one animal had consistently more entodinia and bacteria than the other over a considerable period of time and despite several changes of ration, including a few days' starvation. However, no specific factor could be found in either the saliva or the rumen liquor.

Most of the organisms discussed in this paper, at least when their concentrations 
are highest, can constitute a significant proportion of the microbial protoplasm present. If strained rumen liquor is centrifuged, the deposit usually occupies $10-20 \%$ of the total volume. Part of this deposit is plant material, so it is probable that the microbial protoplasm rarely occupies more than $10 \%$ of the volume of strained rumen liquor, i.e. $10^{11} \mu^{3} / \mathrm{ml}$. From the approximate volumes of the individual cells of different species or groups of micro-organisms given in Table 7 , and the number of cells per ml. given in, e.g. Tables 1 and 2, it can be seen that the bacteria always constitute a large proportion of the total microbial protoplasm, and the other groups usually counted in this work can constitute up to $10 \%$ or even more of the protoplasm. It is to be expected that the proportion of water in the cells should be of the same order of magnitude in the different organisms, and since all groups must be capable of reasonably active metabolism if only to maintain their numbers, it is to be expected that the proportion of enzymically active protein in the total protoplasm should also be of the same order of magnitude. Hence it lollows that most of the organisms discussed in this paper can be expected, on those occasions when their concentrations are high, to make a considerable contribution to the chemical activity of the rumen.

'Table 7. Approximate average volumes of individual cells of rumen micro-organisms

Many of these organisms vary considerably in size depending on their physiological state; where there are several species in the group, as in Entodinium or the bacteria, the different species in the group may have very different sizes; some of these organisms are of irregular shape which makes estimation of their volume difficult. The figure given represents a rough approximation to the more common average size. All the organisms that could constitute a significant part of the total microbial protoplasm in the specimens examined in this work are included in this table.

$$
\text { Organism }
$$

Isotricha, Epidinium, Metadinium, Eudiplodinium spp. $\quad \mathbf{1 , 0 0 0 , 0 0 0}$ Dasytricha, Diploplastron, Diplodinium spp. $\quad 100,000$ Entodinium

Polymastigates

10,000

Oscillospiras, flagellates $\quad 250$

Selenomonads $\quad 30$

Bacteria

When examining a number of animals on the one ration and dietary regime over a period of time, the usual tests of chemical activity in the rumen, digestibility or nitrogen balances, etc., or rumen $\mathrm{pH}$ or ammonia concentration, etc., are found to show moderate quantitative variations between animals or periods, but usually no qualitative differences. A likely cause of these variations lies in differences in the rumen microbial populations. However, as found here, this population varies quantitatively and qualitatively to an apparently very much greater extent than does chemical activity. In endeavouring to explain the presence of minor, but the absence of major differences in chemical activity, it is suggested that the following considerations might apply.

(i) Natural selection would determine that the microbial breakdown of substrate was substantially complete within the limits set by the time available; this time is itself a function of the rate of digestion, being mainly dependent on feed particles reaching an appropriate size for passage down the intestinal tract. Any significant 
differences in the digestion of the one ration might therefore be due to differences in limiting factors such as the ability of the micro-organisms to attack lignified incrustations, or factors governing the rate of passage in the rumen.

(ii) The major end-products of fermentation are substantially the same with different microbial populations. Any primary fermentation product, such as lactic or succinic acid, that is susceptible to further reasonably rapid breakdown will cause an enrichment of organisms capable of attacking it and the final end-products will consist of compounds not readily susceptible to anaerobic fermentation. Similar end-products may thus be produced by a variety of microbial populations; this is probably the reason why defaunated ruminants have usually shown few metabolic differences from normal controls (Becker et al. 1930 ; Dyakov, Vinogradov, Vinogradov \& Bereninov, 1931; Johnson et al. 1944; Pounden \& Hibbs, 1950).

(iii) Bauchop \& Elsden (1960) have shown that different organisms metabolizing the same substrates to the same end-products may have different growth yiclds. Hence the total amounts of microbial protoplasm synthesized in the rumen could well differ with different populations despite similar over-all fermentation patterns. In addition, different kinds of protoplasm have different values to the animal on digestion (McNaught, Owen, Henry \& Kon, 1954).

Finally, just as minor plant constituents such as terpenes or alkaloids may have specific effects on individual species of micro-organisms, so may minor microbial metabolic products have specific pharmacological effects on the host animal.

From this discussion it might then be expected that for ruminants on identical rations and dietary regimes, different rumen microbial populations would have effects on the animal due to processes concerned more with synthesis than with degradation. In the experiments of Moir \& Somers (1957) where different dietary regimes using the same ration led to different rumen microbial populations, the effect on nitrogen or dry-matter digestibility was small, but the effect on nitrogen balance was comparatively large, suggesting that the amounts of feed digested under the various conditions were much the same, but that the products of digestion, especially the synthesized microbial protoplasm, differed.

The causes of these differences in microbial population remain obscure. The most likely general explanation would seem to be that there are a large number of possible, more or less stable microbial populations for any one combination of ration, eating and drinking routine, etc., and perhaps animal, and that relatively small causes can start a process of change from one such population to another.

Effect of prolonged under-fieding. In the experiment described in Table 5, one sheep spent a considerable time on a ration known to be below maintenance level; it was then kept without feel for 4 days and then brought back to a high level of feeding. This treatment resulted in the loss from the rumen of many microbial species previously present; those organisms remaining were found in very large numbers for the ration. The most probable explanation is that the low level of feeding, which in short-term experiments (Table 5) appeared inadequate to maintain microbial numbers, allowed some species to disappear from the rumen when continued for a long period, and that on re-feeding the remaining species multiplied to give about the same total microbial protoplasm as at the start of the experiment. Similar unusual microbial populations might be expected in animals in the field after a drought. 
My thanks are due to Dr N. McC. Graham and Dr J. P. Hogan for access to their experimental sheep and for helpful discussions, and to Mr K. Ayers for technical assistance. The experiment on the effect of a complete change of ration was done at the Rowett Research Institute, Scotland, whilst holding a Grant from the Agricultural Research Council, to whom thanks are due, and was described in a thesis submitted to the University of Aberdeen in 1955.

\section{REFERENCES}

BaUchop, 'T. \& Elsden, S. R. (1960). The growth of micro-organisms in relation to their energy supply. J. gen. Microbiol. 23, 457.

Becker, E. R., Schulz, J. A. \& Fmmerson, M. A. (1930). Experiments on the physiological relationships between the stomach infusoria of ruminants and their hosts, with a bibliography. Iowa St. Coll. J. Sci. 4, 215.

Boyne, A. W., EADie, J. M. \& RaitT, K. (1957). The development and testing of a method of counting rumen ciliate protozoa. J. gen. Microbiol. 17, 414.

Bryant, M. P., Small, N., Bouma, C. \& Robinson, I. (1958). Studies on the composition of the ruminal flora and fauna of young calves. J. Dairy Sci. 41, 1747.

Burrovghs, W., Gall, L. S., Gerlaugh, P. \& Bethke, R. M. (1950). The influence of casein upon roughage digestion in cattle with rumen bacteriological studies. J. Anim. Sci. 9, 214.

Coleman, G. S. (1958). Maintenance of oligotrich protozoa from the sheep rumen in vitro. Nature, Lond., 182, 1104.

Crick, F. H. C. (1948). Cited as personal communication by Hughes, A. F. (1952). The Mitotic Cycle. London: Butterworth.

Dyakov, M. I., Vinogradov, T. V., Vinogradov, M. P. \& Bereninov, A. N. (1931). Influence of infusoria on digestion in ruminants. Izvestiya Tsentral. Nauch- Issledovatel. Inst. Pischevoi Vhusovoi Prom. separate. Cited in Chem. Abstr. (1934) 28, 1756.

EAdIE, J. M., MANN, S. O. \& Oxrond, A. E. (1956). A survey of physically active organic infusoricidal compounds and their soluble derivatives with special reference to their action on the rumen microbial system. J. gen. Microbiol. 14, 122.

Elsoden, S. R. (1945). Volatile fatty acids in the rumen of the sheep. Proc. Nutr. Soc. 3, 242.

Filsolen, S. R., Volcani, B. E., Gilchirist, F. M. C. \& Lewis, D. (1956). Properties of a fatty acid forming organism isolated from the rumen of sheep. J. Bact. 72, 681 .

EL-Tabey Shehata, A. M. (1958). The effect of different rations on the number of free ruminal bacteria in sheep. Appl. Microbiol. 6, 422.

Lmery, R. S., Smith, C. K. \& Lewis, T. R. (1958). Effect of hay-concentrate ratio on rumen fill as measured by an antipyrine dilution technique. J. Dairy Sci. 41, 647.

Gall, L. S., Burroughs, W., Gerlaugh, P. \& Edgington, B. H. (1949). Rumen bacteria in cattle and sheep on practical farm rations. J. Anim. Sci. 8, 441.

Gutierrez, J. (1959). Studies on the culture of the rumen ciliate Epidinium ecaudatum Crawley. J. Protozool. 6, Suppl. 21.

Gutierrez, J., Davis, R. E., Lindahl, I. L. \& Warwick, E. J. (1958). Bacterial changes in the rumen during the onset of feed-lot bloat in cattle. Appl. Microbiol. 7, 16.

Joinson, B. C., Hamilton, T. S., Robinson, W. B. \& Garey, J. C. (1944). On the mechanism of non-protein nitrogen utilization by ruminants. J. Anim. Sci. 3, 287.

Lloyd, L. E., Peckinam, H. E., \& Crampton, E. W. (1956). The effect of change of ration on the required length of preliminary feeding period in digestion trials with sheep. J. Anim. Sci. 15, 846.

Luninsky, G. (1957). Studies on the evolution of the Ophryoscolecidae(Ciliata: Oligotricha). III. Phylogeny of the Ophryoscolecidae based on their comparative morphology, Canad. J. Zool. 35, 141.

McNaught, M. L., Owen, E. C., Henry, K. M. \& Kon, S. K. (1954). The utilization of non-protein nitrogen in the bovine rumen. 8 . The nutritive value of the proteins of preparations of dried rumen bacteria, rumen protozoa and brewer's yeast for rats. Biochem. J. 56, 151. 
MAKI, L. R. \& Foster, E. M. (1957). Effect of roughage in the bovine ration on types of bacteria in the rumen. J. Dairy Sci. 40, 905.

Meiske, J. C., Salsbury, R. L., Hoefer, J. A. \& Luecke, R. W. (1958). The effect of starvation and subsequent refeeding on some activities of rumen micro-organisms in vitro. J. Anim. Sci. 17, 774.

Moir, R. J. \& Masson, M. J. (1952). An illustrated scheme for the microscopic identification of rumen micro-organisms of sheep. J. Path. Bact. 64, 343.

Molr, R. J. \& Somens, M. (195\%). Ruminal flora studies. VIII. The influence of rate and method of feeding a ration upon its digestibility, upon ruminal function and upon the ruminal population. Aust. J. agric. Res. 8, 253.

Moir, R. J. \& Williams, V. J. (1950). Ruminal flora studies in the sheep. II. The effect of the level of nitrogen intake upon the total number of free micro-organisms in the rumen. Aust. J. sci. Res. B3, 380.

Mowry, H. A. \& Becker, E. R. (1930). Experiments on the biology of infusoria inhabiting the rumen of goats. Iowa St. Coll. J. Sci. 5, 35.

Notrle, M. C. (1956). Ruminal flora studies in the sheep. VI. Diurnal, daily and seasonal fluctuations in the concentrations of 'free' rumen bacteria and in rumen pH. Aust. $J$. biol. Sci. 9, 593.

Oxford, A. E. $(1955 a)$. Some observations upon the status of the generic name Selenomonas Prowazek. Int. Bull. bact. Nomencl. 5, 131.

Oxford, A. E. (1955b). Parasitological reviews. The rumen ciliate protozoa. Exp. Parasit. 4, 569.

Pounden, W. D. \& Hibbs, J. W. (1948a). The influence of the ration and rumen inoculation on the establishment of certain micro-organisms in the rumens of young calves. J. Dairy Sci. 31, 1041.

Pounden, W. D. \& Hibbs, J. W. (1948b). The influence of the ratio of grain to hay in the ration of dairy calves on certain rumen micro-organisms. J. Dairy Sci. 31, 1051.

Pounden, W. D. \& Hibis, J. W. (1950). The development of calves raised without protozoa and certain other characteristic rumen micro-organisms. J. Dairy Sci. 33, 639.

Purser, D. B. (1961). A diurnal cycle for holotrich protozoa of the rumen. Nature, Lond. $190,831$.

Purser, D. B. \& Morr, R. J. (1959). Ruminal flora studies in the sheep. IX. The effect of $\mathrm{pH}$ on the ciliate population of the rumen in vivo. Aust. J. agric. Res. 10, 555.

Quin, J. I. (1943). Studies on the alimentary tract of Merino sheep in South Africa. VII. Fermentation in the forestomachs of sheep. Onderstepoort J. vet. Sci. $18,91$.

Scherbaum, O. (1957). The division index and multiplication in a mass culture of Tetrahymena following inoculation. J. Protozool. 4, 257.

SpISNI, D. (1955). Il contenuto di batteri del rumine di pecore ad alimentazione esclusiva con insilato A.I.V. Vet. ital. 6, 1209.

Stross, R. G. (1960). Growth response of Chlamydomonas and Haematococcus to the volatile fatty acids. Canad. J. Microbiol. 6, 611.

Warner, A. C. I. (1956). Criteria for establishing the validity of in vitro studies with rumen micro-organisms in so-called artificial rumen systems. J. gen. Microbiol. 14, 733.

Warner, A. C. I. (1962). Enumeration of rumen micro-organisms. J. gen. Microbiol., 28, 119.

Williams, V. J. \& Moir, R. J. (1951). Ruminal flora studies in the sheep. III. Influence of different sources of nitrogen on the nitrogen retention and on the total number of free micro-organisms in the rumen. Aust. J. sci. Res. B4, 37 .

Williams, V. J., Nottle, M. C., Moir, R. J. \& Underwood, E. J. (1953). Ruminal flora studies in the sheep. IV. The influence of varying dietary levels of protein and starch upon the digestibility, nitrogen retention and the free micro-organisms of the rumen. Aust. J. biol. Sci. 6, 142. 